\title{
Current status of suction lipectomy in Canada: A cross-sectional survey of plastic surgeons
}

\author{
Gaston Schwarz MD FRCSC FACS, Andrea L Pusic MD MHS \\ Department of Plastic Surgery, Royal Victoria Hospital, McGill University, Montreal, Quebec
}

\begin{abstract}
G Schwarz, AL Pusic. Current status of suction lipectomy in Canada: A cross-sectional survey of plastic surgeons. Can J Plast Surg 2000;8(3):94-96.
\end{abstract}

BACKGROUND: Suction lipectomy is the most common aesthetic surgery performed in North America. The safety of the procedure has recently been questioned, particularly with respect to large volume aspiration.

OBJECTIVE: To delineate Canadian liposuction practice patterns and perceived complication rates.

SUBJECTS AND METHODS: A survey was mailed to all plastic surgeons registered with the Canadian Society of Plastic Surgeons. The survey assessed surgeon demographics, hospital admission rates following liposuction, techniques used, wetting solutions, aspirate volumes and complications.

RESULTS: A total of 322 surveys were mailed. The response rate was $44 \%$. Of the 142 surgeons who responded, 119 regularly performed suction lipectomy. They reported that $70 \%$ of patients had suction lipectomy performed on an outpatient basis. Forty per cent of procedures were performed in private clinics. On average, surgeons performed 40 liposuctions/year without ancillary procedures and 27

liposuctions/year with ancillary procedures. Fifteen per cent of surgeons used ultrasound-assisted liposuction as an adjunct to traditional liposuction, although less than $1 \%$ used it exclusively. The ratio of aspirate to infiltrate was 0.25 to one in $45 \%$ of cases, 0.5 to one in $37 \%$, one to one in $17 \%$ and one to one in fewer than $1 \%$. In $69 \%$ of patients, 1 to $2 \mathrm{~L}$ was aspirated, while in fewer than $5 \%$ of patients, more than $3.5 \mathrm{~L}$ was aspirated. Early complication rates were as follows: hematoma and seroma $2.6 \%$, infection $1.3 \%$ and skin loss $0.01 \%$. Contour irregularity was the main late complication, occurring in $12 \%$ of patients. No cases of venous thrombosis, or pulmonary or fat emboli were reported. No deaths were reported.

CONCLUSIONS: Suction lipectomy is performed commonly by Canadian plastic surgeons, with the majority using a wet or superwet technique. In the vast majority of patients, fewer than $3500 \mathrm{~cm}^{3}$ are aspirated. The complication rate is perceived to be low.

Key Words: Liposuction; Suction lipectomy

Situation actuelle de la lipo-aspiration au Canada : enquête transversale auprès des chirurgiens plasticiens

CONTEXTE : La lipo-aspiration est la chirurgie esthétique la plus pratiquée en Amérique du Nord. L'innocuité de cette intervention a récemment été remise en question, surtout dans les cas d'aspiration de matières en quantité importante.

OBJECTIF : Cerner les schémas de pratique canadiens concernant la lipo-aspiration et le taux de complication perçu.

SUJETS ET MÉTHODES : Un questionnaire a été posté à tous les chirurgiens plasticiens membres de la Société canadienne de chirurgie plastique. L'enquête a évalué les données démographiques des chirurgiens, les taux d'hospitalisation faisant suite à une lipo-aspiration, les techniques employées, les solutions mouillantes, les volumes des matières aspirées et les complications.

RÉSULTATS : Un total de 322 questionnaires ont été postés. Le taux de réponse était de $44 \%$. Des 142 chirurgiens qui ont renvoyé le questionnaire, 119 pratiquaient régulièrement des lipo-aspirations. Ces chirurgiens ont indiqué que $70 \%$ des patients subissaient une lipo-aspiration sur une base externe. Quarante pour cent des interventions étaient pratiquées dans des cliniques privées. En moyenne, les chirurgiens pratiquaient 40 lipo-aspirations par année sans modalités techniques d'appoint et 27 lipo-aspirations avec l'aide de modalités techniques. Quinze pour cent des chirurgiens pratiquaient des lipo-aspirations assistées par échographie comme appoint à la lipo-aspiration classique et moins de $1 \%$ l'utilisaient exclusivement. Le ratio des matières aspirées par rapport à l'infiltrat était de 0,25 sur 1 dans $45 \%$ des cas, de 0,5 sur un dans $37 \%$, de 1 sur 1 dans $17 \%$ et de plus de 1 sur 1 dans moins de $1 \%$ des cas. Chez $69 \%$ des patients, 1 à 2 L étaient aspirés, alors que dans moins de $5 \%$ des patients, plus de 3,5 L étaient aspirés. Les taux de complications précoces étaient les suivants : 2,6\% d'hématomes et de séromes, $1,3 \%$ d'infections et $0,01 \%$ de perte de peau. La principale complication tardive était l'irrégularité de la sculpture qui se produisait chez $12 \%$ des patients. Aucun cas de thrombose veineuse, d'embolie pulmonaire ou graisseuse n'a été signalé, ni de décès.

CONCLUSIONS : La lipo-aspiration est une intervention couramment pratiquée par les chirurgiens plasticiens canadiens, qui utilisent majoritairement la technique de liposculpture « humide »ou « hyperhumide ». Chez la plupart des patients, le volume des matières aspirées est inférieur à $3500 \mathrm{~cm}^{3}$. Le taux de complication est perçu comme faible. 
$\mathrm{L}$ iposuction is the most common aesthetic surgery performed in North America (1). The procedure has evolved relatively rapidly, first with the establishment of superwet and tumescent techniques, and most recently with the introduction of ultrasound-assisted liposuction (UAL).

While its popularity as a body sculpting technique has steadily increased over the past two decades, controversy has arisen in the past several years regarding the safety of the procedure (2-5). Although large surveys have documented low complication rates (6-8), several smaller, more recent studies have raised both physician and public awareness of possible severe sequelae such as pulmonary and fat emboli, and myocardial infarction (2-4). A case series of mortalities following liposuction in New York City has been the most recent focus of concern (2).

Previous studies assessing practice patterns and complication rates have been largely based on the American experience $(7,8)$. The objective of the present study was to assess current liposuction practice patterns among Canadian plastic surgeons, as well as perceived complication rates.

\section{SUBJECTS AND METHODS}

\section{Subjects}

A self-administered survey was mailed to all plastic surgeons registered with the Canadian Society of Plastic Surgeons. Surgeons not routinely practising liposuction were asked to provide demographic information only and to return the survey without completing it further.

Demographic data on all members of the Canadian Society of Plastic Surgeons were obtained from the society to allow comparison of responders with nonresponders.

\section{Questionnaire}

The introduction to the survey assessed surgeon demographics and the percentage of surgeons performing liposuction. The remainder of the survey assessed patient demographics, liposuction techniques used, hospital admission rates, wetting solutions, aspirate volumes, use of compressive garments and postoperative complications. The survey was provided in both French and English. Surgeons were encouraged to make additional comments at the end of the survey.

\section{Patient demographics}

The surgeons were asked to report the sex distribution of patients, as well as the number of patients undergoing ancillary procedures at the time of liposuction.

\section{Techniques used}

Surgeons were asked to report the frequency with which they used a liposuction machine compared with syringe liposuction and/or UAL. They were asked to identify the type of infiltration and the average ratio of infiltrate to aspirate used. They were also asked to quantify volumes of aspirates obtained, excluding submental liposuction. Use of postoperative compressive garments and/or massage was also queried.

\section{Complications}

A list of possible postoperative complications was provided, and surgeons were asked to provide percentages seen in their
TABLE 1

Relative frequency of liposuction sites and anesthesia used

\begin{tabular}{lcccc}
\hline & \multicolumn{4}{c}{ Anesthesia } \\
Body parts & \%* & General \% & Local \% & Spinal \% \\
\hline Lateral thigh & 39 & 19 & 69 & 4 \\
Abdomen & 34 & 78 & 22 & - \\
Inner thigh & 28 & 72 & 24 & 4 \\
Inner knees & 24 & 50 & 44 & 6 \\
Flanks-back & 22 & 78 & 19 & 3 \\
Circumferential thigh & 15 & 81 & 11 & 8 \\
Submental & 10 & 21 & 79 & - \\
Calves-ankles & 4 & 69 & 24 & 7 \\
Arms & 4 & 70 & 23 & 7 \\
\hline
\end{tabular}

*Patients may have more than one body area treated, thus the total is greater than $100 \%$

practices. Space was provided for surgeons to list additional complications. They were also asked whether a death had ever occurred in their practice or if they were aware of a death in a colleague's practice.

\section{Statistical analysis}

Response distributions were examined using the ShapiroWilk test. Descriptive statistics based on normal distribution of the response variables were used. Mean values and standard deviations were calculated using Stata statistical software (Stata Corporation, College Station, Texas). Demographic data between responders and nonresponders were compared using Pearson's ${ }^{2}$ test and Student's $t$ test.

\section{RESULTS}

A total of 322 surveys were mailed, with a $44 \%$ response rate. Average years in practice was 16 (SD 8.5), and 90\% of respondents were male. Seventy-one per cent were in solo practice, and 29\% were in group practice. Eighty-five per cent were in a nonacademic setting, and $15 \%$ were in an academic setting. There was no significant difference between responders and nonresponders in terms of either years in practice or sex distribution.

Of the 142 surveys that were returned, 119 surgeons $(84 \%)$ reported that they regularly performed liposuction. Those practising liposuction had been performing the procedure for an average of 11 years (SD 4). Sixty per cent of surgeons operated in private clinics, while $40 \%$ worked in hospital settings.

The surgeons reported that $70 \%$ of patients had their procedure performed as outpatients, and $30 \%$ as inpatients. Eightyeight per cent of patients were female, and $12 \%$ were male (SD 15). The areas most frequently suctioned were the lateral thighs, abdomen and inner thighs, with the majority of procedures being performed under general anesthesia (Table 1).

Surgeons performed an average of 40 liposuction procedures/year without ancillary procedures (SD 15) and 27/year with ancillary procedures such as abdominoplasty or breast augmentation (SD 11). Fifty-six per cent of surgeons used machine liposuction exclusively, while $28 \%$ used a combination of machine and syringe techniques. Fifteen per cent used 
TABLE 2

Volume of aspiration*

\begin{tabular}{lc}
\hline Volume $\left(\mathbf{c m}^{\mathbf{3}}\right)$ & Frequency $\mathbf{( \% )}$ \\
\hline$<1000$ & 35 \\
$1001-2000$ & 34 \\
$2001-3000$ & 20 \\
$3001-3500$ & 6 \\
$3501-4000$ & 3 \\
$4001-4500$ & 1 \\
$>4500$ & $<1$ \\
\hline
\end{tabular}

*Excludes submental liposuction

the syringe exclusively. UAL was used as an adjunct by $15 \%$ of surgeons, while less than $1 \%$ used it exclusively.

Ninety-nine per cent of surgeons used some form of infiltration. Eighty-five per cent used the Hunstad formula, 11\% Klein's formula and $4 \%$ an alternative formula. Forty-five per cent used a ratio of infiltrate to aspirate of 0.25 to one, $37 \%$ used 0.5 to one, $17 \%$ used one to one or greater, and less than $1 \%$ used greater than one to one. In $69 \%$ of patients, 1 to $2 \mathrm{~L}$ was aspirated, while in less than $5 \%$, greater than $3.5 \mathrm{~L}$ was aspirated (Table 2). Ninety per cent of surgeons prescribed postoperative compressive garments, and 30\% recommended massage.

The most frequent postoperative complication was contour irregularity, seen in $12 \%$ of patients (Table 3 ). Seromas and hematomas were the next most common complications, seen in $1.8 \%$ and $0.8 \%$ of patients, respectively. There were no reported mortalities, no venous thromboses, no pulmonary or fat emboli, no myocardial infarctions and no reported abdominal cavity perforations.

\section{DISCUSSION}

The present study suggests that suction lipectomy is performed commonly by Canadian plastic surgeons and that the complication rate is low. Liposuction practice patterns among Canadian plastic surgeons may differ in several significant ways from those in the United States.

Up to $30 \%$ of patients remained in hospital after liposuction, with $60 \%$ of procedures performed in hospital. This is in contrast to the more clinic-based experience in the United States $(3,9)$. The American Society of Plastic \& Reconstructive Surgeons issued guidelines suggesting that patients undergoing large volume liposuction remain in hospital overnight (5). Our findings suggest that this is likely already a standard of practice among Canadian plastic surgeons.

Few Canadian surgeons perform true tumescent liposuction, with the majority using a wet or superwet technique. This may be related to concerns regarding xylocaine toxicity, which has been a recent source of controversy $(2,3)$. In addition, the average volume of aspirate obtained was relatively low, with less than $5 \%$ of patients having more than $3.5 \mathrm{~L}$ aspirated. Because most serious perioperative and postoperative complications are thought to be related to large volume liposuction $(3,5)$, this may be a conservative approach.

There was relatively little use of UAL, either alone or as
TABLE 3

Complications of suction lipectomy

\begin{tabular}{lc}
\hline Complication & Frequency (\%) \\
\hline Contour irregularity & 12.0 \\
Seroma & 1.8 \\
Hematoma & 0.8 \\
Infection & \\
$\quad$ Local & 1.3 \\
$\quad$ Systemic & 0.01 \\
Skin loss & 0.1 \\
Deep venous thrombosis & 0 \\
Pulmonary embolism & 0 \\
Fat embolus & 0 \\
Myocardial infarction & 0 \\
Abdominal perforation & 0 \\
\hline
\end{tabular}

an adjuvant technique. This is in contrast to the American experience, where UAL has gained considerable favour. This may reflect the significant equipment cost associated with starting UAL, less consumer demand or possibly concerns about efficacy and safety (10).

With regard to postoperative complications, the crosssectional survey study design is clearly subject to surgeons' reporting bias. In spite of this potential bias, the incidence of complications was very similar to that reported in other large studies (6,7). In Pitman and Teimourian's (7) 1985 survey, contour irregularity was also the most common postoperative complication, reported in $10 \%$ of patients. The combined incidence of hematomas and seromas was $2.4 \%$, compared with $2.6 \%$ seen in our survey.

Suction lipectomy is one of the most common procedures performed by Canadian plastic surgeons. The complication rate is low, with no deaths or serious complications such as pulmonary emboli or myocardial infarction reported. This may be attributed to the more conservative practice patterns of Canadian plastic surgeons.

\section{REFERENCES}

1. Dolsky RL. State of the art in liposuction. Dermatol Surg 1997;23:1192-3.

2. Rao RB, Ely SF, Hoffman RS. Deaths related to liposuction. N Engl J Med 1999;340:1471-5.

3. Grazer F, De Jong RH. Fatal outcomes from liposuction: census survey of cosmetic surgeons. Plast Reconstr Surg 2000;105:436-46.

4. Daane SP, Rockwell WB. Analysis of methods for reporting severe and mortal lipoplasty complications. Aesthetic Plast Surg 1999;23:303-6.

5. Bruner JG. ASPRS Task Force on Lipoplasty: Brief Statement. Arlington Heights: American Society of Plastic and Reconstructive Surgeons, March 31, 1998.

6. Dillerud E. Suction lipoplasty: a report on complications, undesired results, and patient satisfaction based on 3511 procedures. Plast Reconstr Surg 1991;88:239-46.

7. Pitman GH, Teimourian B. Suction lipectomy: complications and results by survey. Plast Reconstr Surg 1985;76:65-72.

8. Teimourian B, Rogers WB. A national survey of complications associated with suction lipectomy: a comparative study. Plast Reconstr Surg 1989;84:628-31.

9. Joas TA. Sedation and anesthesia in the office setting. Aesthet Surg J 1998; 18:300.

10. Ultrasound-assisted lipoplasty resource guide. <Www.plasticsurgery.org/ $\mathrm{psf} / \mathrm{psfhome} / \mathrm{comm} /$ ualguide/contents/htm $>$. Chicago: American Society of Plastic and Reconstructive Surgeons, November 17, 1998. 